\title{
Krankenversicherung
}

\section{Attraktive Angebote für FMH Services-Mitglieder}

\section{Sparpotential von über CHF 600.-}

Jeder zweite Schweizer zahlt jährlich über CHF 600.- mehr Krankenkassenprämien, als es ihn bei der günstigsten Versicherungsgesellschaft kosten würde. Unser Krankenkassenspezialist überprüft kostenlos und unverbindlich, wie hoch Ihr persönliches Sparpotential ist, und zeigt Ihnen die Spezialrabatte, welche Sie in unseren Rahmenverträgen erhalten können.

\section{FMH Insurance Services-Kollektivverträge mit bis zu $50 \%$ Rabatt auf den Zusatzversicherungen}

Wir freuen uns sehr, dass wir Ihnen bei den folgenden Versicherungsgesellschaften Spezialkonditionen anbieten können:

\section{CSS-Gruppe • Innova • KPT • Helsana-Gruppe}

Profitieren Sie und Ihre im gleichen Haushalt lebenden Familienmitglieder und Konkubinatspartner von den attraktiven Prämienrabatten. Die Alterslimiten liegen je nach Kasse zwischen 60 und 65 Jahren. Kinder können bis Alter 25 mitversichert werden. Die genannten Versicherungsgesellschaften gewähren FMH Services-Mitgliedern auf den meisten Zusatzversicherungen einen Kollektivrabatt von $10 \%$ bis $50 \%$ gegenüber der Normalprämie.

\section{Profitieren Sie von unserem Angebot}

Nutzen Sie die Vorteile der FMH Insurance Services-Kollektivverträge und bestellen Sie noch heute Ihre persönliche Offerte mit dem unten stehenden Antworttalon. Damit wir ein mit Ihrer aktuellen Versicherung vergleichbares Angebot berechnen können, bitten wir Sie, uns eine aktuelle Policenkopie beizulegen. Sind Sie bereits bei einer der genannten Kassen versichert und mit dem Angebot zufrieden? Beantragen Sie bei uns per Telefon unter 0319595011 den Wechsel in den Kollektivvertrag, um auch von den Spezialkonditionen profitieren zu können.

\section{Antworttalon}

Vorname / Name

Adresse

PLZ / Ort

Geburtsdatum

Telefon Privat / Geschäft

Beste Zeit für einen Anruf

E-Mail-Adresse

Ja, ich will Krankenkassenprämien sparen! Bitte senden Sie mir eine Offerte. (Bitte aktuelle Policenkopie beilegen)

Bitte suchen Sie für mich das beste Angebot aus ODER

I Ich möchte eine Offerte der folgenden Kasse (max. 2 Offerten)

O Innova O KPT

O Helsana-Gruppe OCSS-Gruppe

$\bigcirc$ Bitte rufen Sie mich für eine persönliche Beratung an.

Ich interessiere mich für:

$\begin{array}{ll}\text { O Finanz-/Steuerplanung } & \text { O Pensionskasse BVG } \\ \text { O Säule 3a } & \text { O Rechtsschutzversicherung } \\ \text { O Kapitalanlage } & \text { O Berufshaftpflichtversicherung }\end{array}$

O 